\title{
A religious oriented approach to addressing female genital mutilation/cutting among the Somali community of Wajir, Kenya
}

Maryam Sheikh Abdi

lan Askew

Population Council

Follow this and additional works at: https://knowledgecommons.popcouncil.org/departments_sbsr-rh

Part of the Demography, Population, and Ecology Commons, Family, Life Course, and Society Commons, Gender and Sexuality Commons, International Public Health Commons, Medicine and Health Commons, and the Women's Health Commons How does access to this work benefit you? Let us know!

\section{Recommended Citation}

Sheikh Abdi, Maryam and lan Askew. 2009. "A religious oriented approach to addressing female genital mutilation/cutting among the Somali community of Wajir, Kenya," FRONTIERS Report. Washington, DC: Population Council. 
A Religious Oriented Approach to Addressing

Female Genital Mutilation/Cutting among the Somali Community of Wajir, Kenya

(1) Population Council

RENTIERS

USAID 


\title{
A Religious Oriented Approach to Addressing Female Genital Mutilation/ Cutting among the Somali Community of Wajir, Kenya
}

\author{
Maryam Sheikh Abdi \\ Ian Askew
}

Revised Version 2009

This publication is made possible by the generous support of the American people through the United States Agency for International Development (USAID) under the terms of Cooperative Agreement No. HRN-A-00-98-00012-00. The contents are the responsibility of the FRONTIERS Program and do not necessarily reflect the views of USAID or the United States Government.

12 Population Council

FRONTIERS

IN REPRODUCTIVE HEALTH

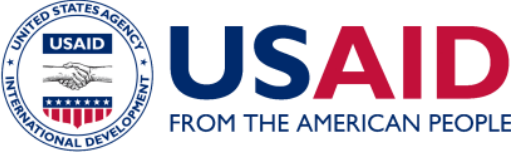




\section{TABLE OF CONTENTS}

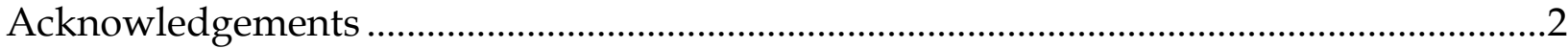

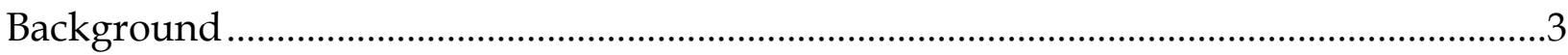

Justification for using a Religious Oriented Approach ………………………………........

Overview of the religious oriented approach ..................................................................

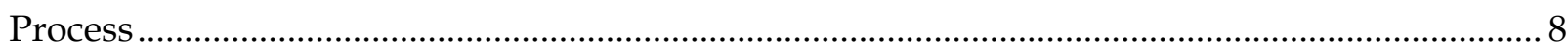

Training different community groups ................................................................................ 9

Discussion topics......................................................................................................

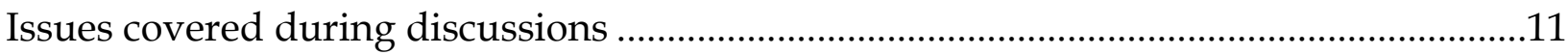

Addressing the underlying reasons for FGM/C practice in the Somali community..................................................................................................................... 11

Is FGM/C an Islamic practice, and is it sunnah for females in Islam?....................................... 11

Islamic upbringing of children (tarbiya) …………………………………………………...... 18

Islam and cultural practices ............................................................................................ 18

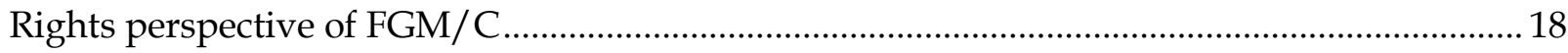

Medical perspective on FGM/C......................................................................................... 19

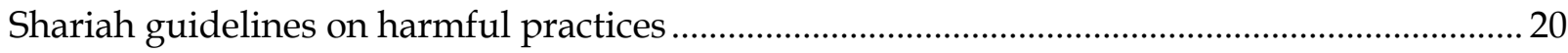

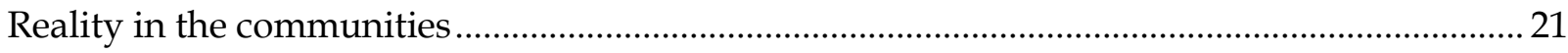

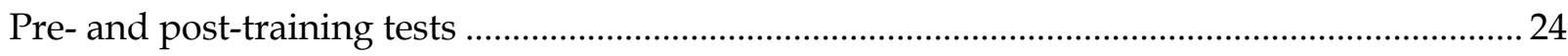

Responsibilities of leaders in the community …………………………………………….... 24

Frequently asked questions ..............................................................................................24

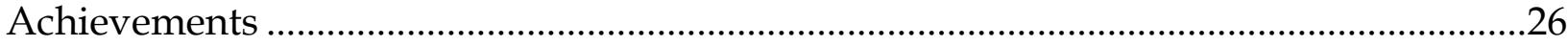

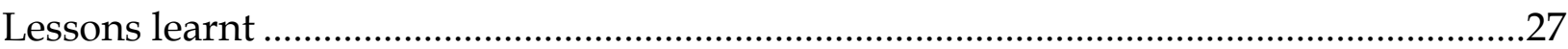

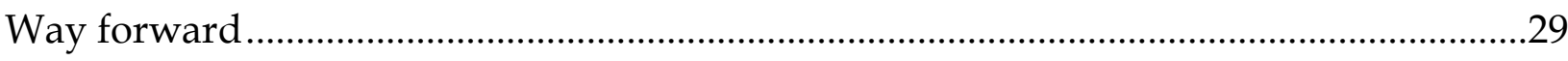

Continue with religious clarifications.......................................................................................... 29

Mainstreaming FGM/C in other development programs........................................................ 29

Strengthen partnerships............................................................................................................... 29

Target the whole community ……………………………………………………………..... 29

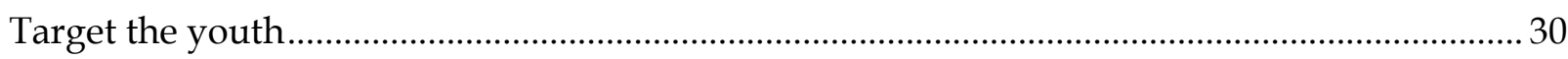

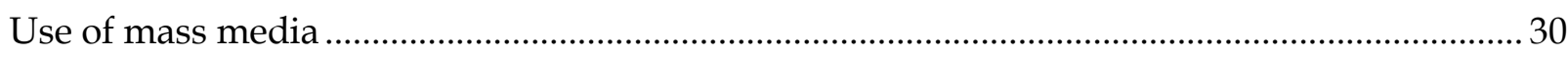

Suggestions for further research........................................................................................ 30

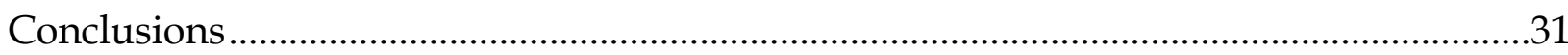




\section{ACKNOWLEDGEMENTS}

We acknowledge the following people who contributed to the write up of this process report.

Sheikh Ibrahim Lethome and Sheikh Khalfan Khamis, consultants with Population Council in Nairobi, were instrumental in laying out the relevant topics needed in community discussions to address the underlying reasons and rationale for the practice of FGM/C among the Somali community. Sheikh Ibrahim also edited the document throughout its development.

Special thanks also go to Laura Raney, formerly of Population Council, Washington DC, for her edits and inputs throughout the writing of the report and Janet Munyasya of Population Council, Nairobi office, for formatting.

We are grateful to the un-named respondents of the community studies carried out in Wajir, Mandera and Eastleigh and participants at the many meetings of Muslim scholars from North Eastern Province of Kenya as well as at the trainings held for various community members in Wajir whose opinions and perceptions helped inform this report.

The authors would like to acknowledge and thank USAID/Kenya for their financial support in the preparation of this document. 


\section{BACKGROUND}

Female genital mutilation (FGM/C), also known as Female Genital Cutting (FGM/C) and Female Circumcision, is practiced in 28 countries of sub-Saharan Africa, a few countries in the Middle East and Asia, and among immigrant populations from these countries in Europe, North America and Australasia. As many as 100-140 million girls and women worldwide have undergone the practice, and at least two million girls are at risk of being cut each year.

FGM/C comprises all procedures involving partial or total removal of the female external genitalia, or other injury to the female genital organs for non-medical reasons ${ }^{1}$. WHO recognises four types of FGM/C, the most severe of which is type III (sometimes known as Pharaonic circumcision ${ }^{2}$ or infibulation). Approximately 15 percent of all cases of genital cutting are of this type. ${ }^{3}$ It consists of the removal of all, or part of, the clitoris, excision of all, or part of, the labia minora, and cutting of the labia majora to create raw surfaces, which are then stitched or held together so that the scar tissue forms a cover over the vagina when healed. Thorns or stitches may be used to hold the two sides of the labia majora together, and the legs may be bound together for up to two weeks. A small opening is left for the passing out of urine and menstrual blood. 4

The Somali ethnic community, in Kenya as well in Somalia, Djibouti and Ethiopia, has practiced genital cutting for centuries and the practice appears to have remained largely unchanged. The 2003 Kenya Demographic and Health Survey (KDHS) ${ }^{5}$ found a prevalence of 96.8 percent among Somali respondents and 98.9 percent for the North Eastern Province (NEP) where the majority live. The community practices the severest form of FGM/C, type III or infibulation.

The Population Council's FRONTIERS program, with support from USAID/Kenya, carried out two studies to better understand the practice of FGM/C among the Somalis in North Eastern Province so as to inform the design and implementation of interventions to encourage abandonment of the practice ${ }^{6}$. The first diagnostic study was carried out in Mandera and Wajir districts and Nairobi's Eastleigh area in 2004. The second, a baseline study, was carried out in November 2005 in six locations in the Central Division of Wajir District. Both studies collected data through in-depth interviews and focus group discussions with community and religious leaders, as well as with recently married and unmarried men and women. The first study also interviewed health care providers, undertook an assessment of their clinics'

1 WHO 2007 "Eliminating Female Genital Mutilation: An Interagency Statement"

2 The term is used because this form of genital cutting is thought to have been introduced by the Pharaohs of Egypt.

3 WHO. 1996. "Female Genital Mutilation: Report of a Technical Working Group," Geneva: WHO.

4 WHO. 1995. "Classification and Definitions of Female Genital Cutting," Geneva: WHO.

5 Central Bureau of Statistics (CBS) [Kenya], Ministry of Health (MOH) [Kenya], and ORC Macro. 2004. Kenya Demographic and Health Survey 2003. Calverton, Maryland: CBS, MOH, and ORC Macro.

6 Jaldesa GW, Askew I, Njue C, Wanjiru M. Female genital cutting among the Somali of Kenya and management of its complications. Population Council: Nairobi, Kenya and ${ }^{6}$ FGM/C Baseline Study, Wajir District, 2005 
readiness to offer safe motherhood and FGM/C-related services, and interviewed antenatal clients who had been cut.

These studies confirmed that FGM/C is a deeply rooted and widely supported cultural practice that is shrouded in many cultural reinforcements for its continuation. Several closely related reasons are used to sustain the practice, with two main ones being that it is a Somali tradition, and the belief that it is an Islamic requirement. The use of infibulation is said to enforce the cultural value of sexual purity in females by controlling female sexual desires, thereby ensuring virginity before marriage and fidelity throughout a woman's life. It was evident from the studies that there is the fear of women "running wild" and becoming promiscuous if not circumcised. This was erroneously taken as being in compliance with the Islamic requirement of chastity and morality. The practice is also believed to enhance women's cleanliness. FGM/C plays no role as a rite of passage in the community, as girls as young as four years are subjected to it.

FRONTIERS has developed a religious oriented approach to engage with and educate the community about FGM/C with the aim of encouraging them to question why the practice is sustained and move towards abandoning it. This approach has brought together the religious scholars in Wajir and other senior Islamic scholars within Kenya to debate the correct position of this practice within Islam and also borrow Shariah guidelines that are in essence contradicted by the practice, to educate the community. The myths and misconceptions around the practice, its purpose and thus perceived benefits can best be tackled with both religious and medical arguments. 


\section{JUSTIFICATION FOR USING A RELIGIOUS ORIENTED APPROACH}

The purpose of this approach is to educate the community on the harms of FGM/C, both religiously and medically, so that they question the rationale for its continuation. This strategy is meant to generate discussion with respect to the correct position of Islam on FGM/C and hopefully build consensus among the religious scholars on this matter. The religious scholars command much respect, influence opinions in the Somali community, and are therefore instrumental in educating the community. To unearth and correct the misconceptions surrounding FGM/C and Islam, it is imperative that the religious leaders are involved. Once this is achieved, these scholars can become community educators in encouraging the abandonment of the practice by questioning the whole practice against the backdrop of Islam and answering the question: Does the practice, in all its types, have any authentic basis in Islam?

The belief that there is a sunnah type of FGM/C in Islam is held firmly and this can only be questioned using Islamic teachings. At present, the religious scholars and the wider community unanimously reject infibulation on the basis that it is haram (unlawful) in Islam. However they are supportive of some form of cutting, however mild, as they believe it is a religious requirement and refer to it as sunnah.

\section{"it is part of the religion...sunnah is a must" and that "one who is not circumcised is not a Muslim, and even her parents are seen as not being in the religion, that is how we see as Somalis" (Married men, Wajir 2005)}

Belief that it is a religious requirement is so strong that women are ready to continue with the practice if there is any solid evidence that it is Islamic, notwithstanding its harmful effects. In her narration of her personal experience of FGM/C during one of the discussion sessions with religious scholars from Wajir, one woman said:

"The harms are there. I was in shock for two days. When I started my periods I was in problems. I was done the sunnah of that time even though the place was infibulated. Is there a Quranic verse on this cut? If it is there, then there is no two ways about it, we have to continue doing it, but if it is not there, then you scholars guide us. When I was married I had to be opened up. Whenever I give birth I am cut open" (Wajir, August, 2006).

There are two problems with this: the so-called sunnah FGM/C is not defined and nobody can tell for sure how it is to be carried out. Secondly the community has always claimed to practice the sunnah cut when the actual practice has been excision (cutting all the external organs in the female genitalia) and infibulation:

"In the old days, once the clitoris and the other flesh around it were cut, the place was stitched using thread and needle and or thorns. During our time we were cut and applied with malmal ${ }^{7}$ but there was no stitching or thorns. Our legs were bound

7 Malmal is a traditional medicinal herb that is used on wounds, boils, cuts etc. In this context it used on the cut genitalia as it is believed to aid the infibulation. 
together for weeks and this healed the wound together thereby causing infibulation. This was considered sunnah then but it was still pharaonic. Nowadays, this practice is still on and majority of the people do it..." (Wajir, August 2006).

The first step in the approach is to de-link FGM/C from Islam by critically examining the evidence given for the practice. It is important for the community to understand the Shariah implications of this practice and be made aware of the fact that Islamic Shariah upholds human rights and dignity and that FGM/C violates these rights.

As long as this practice is wrongly justified as Islamic, nothing else will make sense to the community, not even the many international instruments, protocols and legislations that prohibit and outlaw the practice. These are man-made laws according to them and hence they cannot bind them. When asked whether the legislation that prohibits the practice in Kenya was able to make the community abandon the practice, respondents in one of the study were quick to point out that,

"There is a barrier between us and the government and that is our religion.... we are governed by our religion and we don't care about other laws. We will follow our religion...we will not stop sunnah but anything more than what is mentioned in the Quran we can stop. We are ready to discuss with sheikhs but we will not stop because the radio or the government has said" (Married men, Wajir, 2005).

But are there any divine laws that actually support this practice? We can answer this question by weighing the practice against Islamic teachings and proving that there is no sunnah ${ }^{8} \mathrm{FGM} / \mathrm{C}$ in Islam. Knowledge that the practice is traditional and is in conflict with Islamic principles is a sure convincing way that can help in questioning the practice.

Considering the deep belief that FGM/C is a critical component of Somali culture and a perceived religious requirement, efforts to encourage behaviour change cannot focus solely on education about health and rights alone but these arguments can only come in to complement the Islamic stand on FGM/C. For instance, arguments around the health problems that arise from FGM/C alone are not convincing for the community to abandon the practice as these are considered a result of God's will. It is believed that anybody is likely to get such problems regardless of whether or not they have undergone FGM/C. When asked whether they thought there were any complications arising from FGM/C, some respondents in the baseline study asserted that indeed women got tears during childbirth. But others were quick to state that,

"...there is nobody who does not get torn, but it is not because of circumcision, it is God's will and it can happen to any one" (Circumcisers, Wajir, 2005).

Other respondents further claimed that the so-called sunnah circumcision was actually a right, and hence girls have to undergo it. As a result arguments around its

8 Sunnah in this context means the type of FGM/C said to be legitimate in Islam that includes cutting the tip of the clitoris. 
violation of the girls' and women's rights will not be convincing enough unless tied to the human rights provisions in Islam.

\section{"Islamically, it is a right to circumcise girls" (Married men, Wajir, 2005) \\ "... But the religion says it (circumcision) is a must so it is human rights" (Women's Group Leader, Wajir, 2005) \\ "We agree (that FGM/C is a human rights issue) because we want circumcision to continue" (Circumcisers, Wajir, 2005).}

In summary, this religious oriented approach has been developed because:

- In the Somali community the practice is not a rite of passage, as it is carried out on girls as young as four years. Strategies such as the Alternative Rites of Passage (ARP) will not be applicable in this community.

- The medical complications, though known to the community, are considered a result of the will of God and not associated with the practice. It is believed that such complications and problems can happen to anybody, regardless of their FGM/C status. Arguments around the medical complications alone arising from FGM/C would not be convincing enough to help the community question and stop FGM/C. However these medical complications can be blended with Shariah guidelines on the sanctity of the human body and prohibition against cutting healthy organs and causing harm.

- The international, regional and national laws, legislations and protocols enacted to counter the practice are considered to be man-made, and are therefore superseded by beliefs in divine laws. The community was categorical and said that they were ready to listen to religious scholars to tell them what the correct position of Islam was on the practice and that they would be willing to abandon anything un-Islamic.

- The practice is considered a 'right', and hence arguments around it being a violation of the rights of women and girls cannot help in questioning the practice on their own. But if these arguments are tied to Islamic provisions, then it would be easier to question something that violates others' rights and amounts to sin in Islam. 


\section{Process}

Activities under the community-based intervention begun with discussions between religious scholars. Three discussion sessions, in small groups of a maximum of thirteen persons, were held for educated scholars in Wajir district and a larger number at a regional and a national symposium (see table below). These scholars were chosen on the basis of their educational levels whereby those invited to the debates were required to have at least a Diploma or Degree in Islamic Studies and able to speak fluently in Arabic. Knowledgeable scholars from other Muslim communities that do not practice FGM/C facilitated the sessions. Non-Somali scholars were chosen as facilitators to avoid any cultural prejudices that might blind the impartiality of the Somali scholars if they were to facilitate the sessions. Few scholars were chosen for debates, especially at district level, to ensure that the discussions were objective (no mob-psychology and defending a held mindset with no objectivity) and that Islamic Shariah formed the basis for debate.

\section{Consensus building meetings with scholars}

\begin{tabular}{|c|c|c|c|}
\hline DATE & VENUE & $\begin{array}{c}\text { NO OF } \\
\text { PARTICIPANTS }\end{array}$ & ORGANIZATION \\
\hline May $13^{\text {th }}$ to $15^{\text {th }} 2006$ & Garissa & 6 & Population Council \\
\hline June $5^{\text {th }}$ to $7^{\text {th }} 2006$ & Wajir & 12 & Population Council \\
\hline July $7^{\text {th }}$ to $9^{\text {th }} 2006$ & Wajir & 13 & Population Council \\
\hline August $15^{\text {th }}$ to $17^{\text {th }} 2006$ & Wajir & 13 & Population Council \\
\hline $\begin{array}{l}\text { September } 12^{\text {th }} \text { to } 14^{\text {th }} 2006 \\
\text { (Regional Symposium) }\end{array}$ & Garissa & 25 & $\begin{array}{l}\text { Population Council and } \\
\text { UNICEF }\end{array}$ \\
\hline $\begin{array}{l}15^{\text {th }} \text { to } 19^{\text {th }} \text { June } 2007 \\
\text { (National symposium }\end{array}$ & Mombasa & 55 & $\begin{array}{l}\text { Population Council, } \\
\text { UNICEF/Kenya, } \\
\text { UNFPA/Kenya, GTZ and } \\
\text { CIPK }^{9}\end{array}$ \\
\hline
\end{tabular}

The regional scholars were drawn from the four districts of North Eastern Province (Garissa, Wajir, Mandera and Ijara), and from the neighbouring districts of Moyale, Marsabit, Isiolo and Tana River. This was because the communities in these areas are predominantly Muslim; they practice the same type of FGM/C, and put emphasis on the perceived religious requirement as a reason for carrying out FGM/C. It was also meant to create synergy for information sharing and common understanding among the scholars in this region, besides being a way of creating local networks that can help counter the force of the FGM/C proponents. A scholar from Saudi Arabia was a guest speaker at the regional symposium while a scholar from Sudan was a speaker at the national symposium.

9 Council of Imams and Preachers of Kenya (CIPK). 
The objectives of the discussions for the scholars were:

1. To scholarly debate and discuss the place of FGM/C, and more so the socalled sunnah type in Islam, so as to question the reasons, both apparent and underlying, for practicing FGM/C.

2. To come up with a way forward for community education and awareness creation on FGM/C with the aim of encouraging abandonment of the practice.

\section{Training different community groups}

Community members and groups were mobilized and trained as shown below. The objectives of the training sessions for community groups were to de-link the practice from Islam and present it as a cultural practice which is in conflict with Islamic teachings. This was to help them question the rationale for a practice that goes against their belief system and one with no benefits. A total of 1,245 persons were reached in the training that followed a sequence similar to that for the religious scholars:

1. 458 youth (including 350 girls in Wajir Girls' secondary school)

2. 33 men leaders

3. 46 women leaders

4. 43 education officers from NEP (in collaboration with UNICEF/Kenya Garissa office)

5. 198 primary school teachers

6. 91 Traditional Birth Attendants (TBAs) ${ }^{10}$ and cutters

7. 227 women from six women groups

8. 113 Police officers

9. 36 professional women (in collaboration with UNICEF/Kenya Garissa office).

\section{Discussion topics}

Topics that established the non-Islamic nature and basis for FGM/C were discussed in all sessions, both with religious as well as community groups. These topics were selected to help in questioning the rationale for the practice and were derived from the study findings. The first step in this process was to clarify the correct position of Islam on FGM/C by looking at what the proponents use as the evidence for the practice in Islam. This was to address the widely-held belief that the practice was Islamic, as had been revealed by both the diagnostic and the baseline studies. The second step was to pull together guidelines and Shariah teachings that are contradicted by the practice to show that FGM/C is in violation of Islam in order to question the underlying reasons for FGM/C practice in the community.

10 Some of the TBAs double up as cutters/circumcisers in the community. 
The overall structure of the discussions for both the scholars and the other community groups was as follows:

- Clarifying the correct position of Islam on the practice

- The correct position of Islam on FGM/C was examined by looking at the evidence used by proponents of the so-called sunnah type. The evidence consists mainly of ahadith ${ }^{11}$. A critical examination of the status of the evidence was done in the discussions so as to provide proof for the nonIslamic basis of FGM/ $\mathrm{C}^{12}$

- The extent of the so-called sunnah type

- Why FGM/C is necessary for women

- Islamic teachings on women and enjoyment of sex

- Islamic guidance on control of sexual desires

- What is the verdict on the faith (Islam) of those who do not support, practice or believe that FGM/C is a sunnah?

- Come up with a list of other topics that help show the un-Islamic nature of the practice

- Islam and cultural practices

- Islam and human rights

- Shariah implications of harmful practices

- Islamic guidance on proper upbringing of children

- Legal perspective to also show FGM/C is in breach of the laws of the country

- Medical perspective

- A plenary session after each discussion to ask questions, raise issues and clarify misconceptions

- Reality in the community

- Evidence from baseline study

- Visual evidence (video documentary showing infibulation)

- Circumciser's testimony

- Personal experiences

- Responsibilities of persons especially leaders in correcting ills in the community.

11 Ahadith is the plural of Hadith (recorded sayings and practices of the Prophet Mohamed)

12 Lethome I and Abdi. M, 2008 Delinking Female Genital Mutilation/Cutting from Islam, FRONTIERS, Population Council: Nairobi, Kenya. 


\section{Addressing the underlying reasons for FGM/C practice in the Somali community}

In all trainings the underlying reasons were discussed as a first step. Below are the reasons given for practicing FGM/C among the Somali community captured in the studies.

\section{Is FGM/C an Islamic practice, and is it sunnah for females in Islam?}

This topic was chosen to address the widely-held belief that there is a "mild" type of FGM/C called sunnah that is allowed in Islam. This was a strongly held belief and in the baseline study of 2005, respondents said that, "One who is not circumcised is not a Muslim, and even her parents are seen as not being in the religion, that is how we see as Somalis", (Married men, Wagberi).

The discussions always began from a known fact that any matter that is Islamic must be supported by evidence from the primary sources of Shariah i.e. the Quran, sunnah ${ }^{13}$, consensus by scholars (ijma) and analogical deductions (qiyas). Hence if FGM/C is to be considered Islamic, it must have supporting evidence in these sources.

- There is nothing in the Quran that can be used as evidence for FGM/C. The proponents often quote the verse, "... and follow the religion of Abraham inclining towards truth..." (Quran: 4: 125). They claim that since Prophet Ibrahim (Peace Be Upon Him-PBUH) was circumcised at the age of eighty (80) years in obedience to Allah's command, then Muslims should follow suit as they are

13 As a source of Islam, sunnah means ways of life of Prophet Muhammad (PBUH) derived from his sayings, actions and approvals.

\section{Reasons for practising FGM/C among the Somali}

1. Somali tradition

"It is our tradition that a girl must be circumcised and stitched..." (Married women, Wajir Baseline study).

\section{Islamic requirement}

"The fear is that the men would consider such women as nonbelievers. So they must undergo the cut and be stitched to Islamise them. Actually most women would not talk of circumcising but only Islamise their daughters as though the lady was a pagan. So that is the reason." (FGM practitioner).

\section{Sexual control}

"Almighty God created sexual desires in ten parts and he gave nine parts to women and only one to men" (older men, FGD)and that those who are not cut "....will start chasing men because of her uncontrollable sexual urge, excessive sexual desire, she will be very vulnerable, she has no security and [will] subsequently [be] disgraced. Circumcised girls will not go for another man because this her husband will trust her." (FGM practitioner).

4. Beautification of the genitalia

"I will circumcise my daughter because I want her to be beautiful and her thing [to be] shiny like a mirror" and "[The] female body is like a house and a house needs to be decorated. It is like making a door of a house look better. This is good for both the lady and the man who will marry her..." (Female respondents).

5. Ensures cleanliness

"Those who are not circumcised are dirty, and they will always produce a foul smell, so we are circumcised to be kept clean." (Newly married women FGD).

\section{Protects/preserves virginity}

"The Somali culture wants the girls to be virgins. If the girls had Sunna type of circumcision, the virginity can break by itself. That is what worries people because we have seen men who if they find the girl has not been stitched leave her in the morning and say how will I ever believe her again. They will only believe she was a virgin if she was stitched." (Recently married women FGD).

\section{Marriageability}

"If the girl is not circumcised, however beautiful she is, she is not wanted by men. He wants or prefers the stitched one, who [he] will be happily busy with through the night. But he will not be happy with the open one. I will do whatever will make them like my daughter, I will stitch her up tight" (Elderly men FGD). 
directed in the verse. This claim is countered by the fact that the practice of Prophet Ibrahim (PBUH) is evidence for male circumcision and not for FGM/C as there is no authentic evidence that any of the women in his household were circumcised.

- As far as the Sunnah is concerned, the ahadith relied on are either not authentic or relevant, and can therefore not be used as a basis for such a sensitive issue ${ }^{14}$. Those that are authentic are unrelated to FGM/C and hence cannot serve as evidence for the practice. The facilitators then took the discussion through these ahadith and showed how these are either unreliable (due to their weak status) or unrelated to the subject of FGM/C, thereby negating the link or basis of FGM/C in Islam. They also picked on the example from the household of Prophet Muhammad (PBUH) where there is clear evidence of male, including his own grandsons', circumcision but not FGM/C, hence the practice cannot be his sunnah.

- There is no consensus (ijma) on FGM/C from scholars. Proponents base their support for FGM/C on views of the four schools of thought and these schools have different opinions based on their understanding and interpretation of the same un-authentic or inapplicable ahadith.

- According to the Hanafiya it is a sunnah ${ }^{15}$ (optional) for both males and females, whereby those who observe it are rewarded while those who do not have not sinned

- Malikiya hold the view that it is wajib (obligatory) for the men and sunnah (optional) for the women

- Shafiiya say it is wajib (obligatory) for both men and women.

- Hambaliya have two opinions: it is wajib (obligatory) for both men and women; it is wajib (obligatory) for men and makrumah (honourable) for the women.

- Qiyas ${ }^{16}$ (analogical deduction) is not applicable because FGM/C cannot be compared with male circumcision. Whereas male circumcision has strong basis in Shariah and therefore a religious requirement, FGM/C has no basis and is not an Islamic practice. Besides, there is a difference in what is cut. In males it is the foreskin, in females it is functional organs. Moreover, male circumcision has both religious and medical benefits whereas FGM/C has religious and medical harms ${ }^{17}$.

Examples were then drawn from the households of Prophets Ibrahim and Mohamed (Peace Be Upon Them) to show that none of the females in these households were subjected to FGM/C yet evidence is there for male circumcision. This was to show

14 Lethome and Abdi, 2008.

15 Sunnah in this context means an optional religious act which carries rewards when done by a Muslim.

16 Qiyas is drawing a comparison between two different things or events that have so much in common and can hence share the same verdict e.g. alcohol is haram by a verse of the Quran because it is an intoxicant, any other intoxicants share the same verdict through analogy.

17 Lethome and Abdi, 2008. 
that had the practice been Islamic, then evidence would have been found in these Holy households.

The knowledge that the practice has no basis in Islam and that it actually contradicts Islamic teachings hence resulting in sin is very powerful and many community members were moved to have a mind-change there and then. In a forum that brought together women professionals from North Eastern Province (NEP) one lady who has been very active in civil society issues, still had the mindset that FGM/C was Islamic and wanted to take her only daughter through FGM/C. She said,

"May Allah reward you sheikh (referring to the consultant who gave the Islamic perspective of FGM/C) for the beautiful lecture. You have saved me from lots of questions in the hereafter and you have saved my daughter from being cut. I was planning to cut her in December this year" (Proffesssional Women's Forum, March 2008)

During a forum for youth, one male youth said:

"We are grateful for the information and I am sure we will stop FGM. I want to state here that I have three daughters and nobody will cut them. I will make sure of this" (Male youth, April 2008).

The practitioners were also touched and had this to say:

"...Today I have learnt the truth. I have always heard that fir'oni was un-Islamic but continued with it. Telling me that even a pin prick is bad and I am responsible for the blood is worrying me. I will repent and I want you all to pray for me. I have been sinning," (FGM/C Practitioner, October 2007)

In the discussion sessions, several other questions were then asked to enable participants start questioning the rationale for FGM/C:

\section{What is the extent of the sunnah type?}

Proponents of the practice were asked to give the extent of genital cutting for the socalled sunnah type and what the exact organ to be cut is. From the meetings, the following different descriptions of the sunnah type were given, both by scholars and the other community groups:

- Cutting a small part or the head or the tip of the clitoris

- Cutting the whole of the clitoris

- Cutting the skin above the clitoris

- Cutting the parts that appear from the female genitalia and resemble the comb of a cock

- Cutting a part of the clitoris and this they say is possible because it (clitoris) has demarcations like the joints of the fingers

- Cutting a quarter of the clitoris (apportioning the clitoris into four equal parts then cut one part)

- Cutting a third of the clitoris 
- Cutting the 'black' head of the clitoris

- Cutting the soft skin on the clitoris.

- Cutting the skin at the end of the clitoris.

- Pricking with a pin to shed some little blood

- Anything that can be called a cut on the female genitalia

Facilitators then raised questions on how this was to be measured and the fact that if this practice was Islamic then it would have an exact specification just as the male circumcision is clearly defined. Women participants gave an account of them being infibulated yet they believed that the sunnah was done. Consensus was that because of lack of knowledge on the exact extent of the so-called sunnah type, this has opened the window for infibulation to thrive despite being shunned as un-Islamic by all ("...I have been cutting girls for over 30 years...I have always heard that fir'oni was un-Islamic but continued with it..."A practitioner, October 2007).

This discussion was then linked to the understanding that the practice, in all its types, has no basis in Islam.

\section{Why is $\mathrm{FGM} / \mathrm{C}$ necessary for women?}

This question was asked to unearth the underlying reasons for the practice i.e. control of female sexual desires. The only benefit or reason the proponents of FGM/C gave was that it controls women's sexual desires (as one participant in one of the sessions put it, "it contains the 'fire' of desire burning within the women" Wajir, June, 2006). This, they said, is necessary as it makes the women chaste thereby upholding their honour and fulfilling the religious requirement of chastity. The fear is that uncut women will have high sexual desires and therefore

"...will start chasing men because of her uncontrollable sexual urge, excessive sexual desire, she will be very vulnerable, she has no security and [will] subsequently [be] disgraced. Circumcised girls will not go for another man because this, her husband will trust her." (FGM/C practitioner)

\footnotetext{
"We have always known that if girls were not cut, then they will run after men and be disgraced. You young girls of today know nothing and you want to confuse us. We shall 'make' the girls properly so that they do not misbehave. This world is very bad and it is not safe even for those who are cut and stitched. We do not want to cause havoc in society by letting loose uncut women who can rape even small boys. We shall cut them! (FGM/C practitioner's training, October 2007)
}

Proponents also said that the practice enhances women's spiritual purity and is important for their tohara (state of physical and spiritual purity). 
These arguments were then countered with the following Islamic teachings:

- Muslim women, just like the men, are supposed to control their sexual desires and only indulge in sexual activity under the lawful umbrella of marriage. There are no physical means to control these desires but Islam places emphasis on moral education and good upbringing (tarbiyya).

- Muslim women have a right to enjoy their matrimonial sexual relations. Hence the so-called sunnah circumcision (whose benefit, in view of its proponents, is to reduce sexual desires in the women) will be going against this basic right for the woman.

- The Shariah guideline in the administration of punishment is that it is not administered until a crime is proven to have been committed. If it is proven that certain women have fornicated or committed adultery, only then will Shariah judge them accordingly ${ }^{18}$.

- A common question was often asked the participants: should people's hands be cut for fear that they might steal19? Participants always said that that would be absurd and inhuman. Then a logical deduction will be made that it was inhuman to start cutting parts of the female organs for fear that they might indulge in sex outside marriage.

- The Somali saying: gacan wax qaad baratay hadii la goyana gumudkaa dhaqdhaqaqaa (even if the hand that steals is cut, its base will still shake) was used to explain further that no amount of cutting of organs would stop one from doing what they have decided to do.

- The medical expert would then come in to explain that it is the brain responsible for the actions of people and not other organs. Therefore for one to indulge in sex, the brain is the major player as opposed to the genital organs.

- Every soul is responsible for its deeds. Women cannot bear the burden of upholding chastity in the community, worse still, if this was to be obtained through cruel ways as is the case with FGM/C. They will be judged, individually, just as the men are, for their own wrongs and rights.

- Women have a right to a healthy body and nobody has the right to inflict pain and/or cut any parts of her body for no apparent reason. The facilitating scholars always reminded the participants that blood money is due on those who carry out these practice and on those who are in position to correct and are not doing so. Hence the following persons are answerable for the blood of the mutilated girls:

- The parents of the girl

- The cutter

- The scholar whose work is to correct and educate the community against ills but who is not doing so

- Any other leader or person in positions of influence and is quiet about the ongoing practice. 
Other underlying reasons for the practice were also countered with guidance from Islam.

- The issue of beautifying the genitalia was countered with the Quranic verse "Verily we created man of the best stature" (Quran: 96:4) and participants would be reminded that they are not any cleverer than the creator (which often resulted in murmurs of prayer seeking forgiveness) and that they should avoid mockery of the genitalia and giving it lots of names as it was part of the human body that the creator said was made in a perfect form. Facilitators would then conclude that the beauty of a human body, and in this case the beauty of the female genitalia, is by leaving it as it was created unless there is an authentic basis allowing interference with it in any way.

- As regards hygiene and cleanliness, participants would be shown pictures of infibulation and how it makes it hard to maintain genital hygiene as urine and menstrual blood pass underneath the closed skin and it is not easy to clean. Urine is one of the spiritual impurities in Islam; thus the woman's tohara is affected as opposed to the belief that it is enhanced.

- Marriageability was also discussed in relation to control of sexual desires and preservation of virginity. This is engrained and intertwined with issues of gender relations which were discussed, especially regarding the worth and value of women and girls in the community, drawing teachings on the equality of human beings as stipulated in Islamic teachings. Participants would be reminded of the primary purpose of creation using the verse, "I have only created jinns and men that they may worship me..." (Quran: 51:56) hence all persons are primarily supposed to strive to worship not other worldly affairs and not torture themselves. Consensus was often reached that it is not true that Somali men will not marry if the females were not taken through FGM/C. Examples would be drawn from the community, sometimes of Somali prominent men, who married women from other communities who do not cut females, notably the Coastal Swahili and Arabs.

\section{Islamic teaching on women and enjoyment of sex}

This was an important discussion to further correct the belief that FGM/C is necessary to control women's sexual desires. In all the sessions, it was always acknowledged that a Muslim woman has the right to enjoy sexual relations and intercourse with her husband, with evidence from the sources (Quran and authentic sunnah ${ }^{20}$ ). Muslim men are required to sexually satisfy their wives. Reference was always made to the fact that, under Islamic law, denial of sex by either wife or husband is a ground for divorce. Medical experts would confirm that FGM/C, in all its forms, interferes with the sexual functioning of the women thereby affecting the attainment of sexual enjoyment and satisfaction, hence is a violation of women's divine right.

20 Lethome and Abdi, 2008. 


\section{Islamic guidance on control of sexual desires}

This session was meant to inform the participants that every Muslim is required to control their desires and a woman, just like a man, is supposed to control her desires, whether sexual or otherwise, by observing the teachings of Islam. With help from a medical expert, participants were informed that cutting of the sexual organs does not control desires, as it is the brain that controls them. In fact, one medical expert was categorical in one of the meetings and told the adamant supporters of FGM/C that if they wanted their daughters not to think of sex then they should chop off their heads and not their clitoris.

The facilitators reminded the participants that Islam lays emphasis on the proper upbringing of children (tarbiyya) and providing moral teachings to followers, right from when they are young. They reiterated that Islam does not teach control of desires through any physical means such as mutilation. An example was picked from the reality that some women from within the community, who have been subjected to the worst type of FGM/C (infibulations), have been known to indulge in sex outside marriage. It was emphasized that without any moral teachings and guidance, no amount of cutting or infibulation can ensure chastity. Examples were also drawn from communities that do not cut and where the women are morally upright to emphasize the message that it is the brain and not the genitalia that is responsible for desires and control.

Female participants in the sessions were asked why they do not run after men and indulge in extramarital sex. They always agreed that it is because they know when sex is lawful and/or unlawful for them. Women were also instrumental in informing men that they desire sex just like any other women, despite being circumcised, but they can control themselves. The medical experts also added that women are stronger in controlling themselves than men.

\section{What is the verdict on the faith (Islam) of those who do not practice FGM/C?}

This question was brought up to help counter the belief that all Muslims carry out sunnah FGM/C on their females ${ }^{21}$. It was meant to show that there are many Muslims from communities who do not cut and to whom this is a foreign practice. There were varied responses to this question. Some participants stated that it is wrong for any Muslim to leave the sunnah type and therefore those not cutting were sinning. However this notion was countered by some of the die-hard supporters of FGM/C who said that because the practice was sunnah (optional), Muslims have the choice to practice it or not.

The session was then concluded with remarks from the facilitators that the practice has no basis in Islam and therefore nobody can be held accountable for not doing it, reminding those doing it that they are in fact straying from what Islam teaches and were therefore sinning.

21 Jaldesa G. et al 2005. "Female Genital Cutting among the Somali of Kenya and Management of its Complications" FRONTIERS, Population Council: Nairobi, Kenya. 


\section{Islamic upbringing of children (tarbiya)}

This topic was discussed at length to emphasise the importance that Islam puts on the proper moral teachings that can make children upright Muslims and that this will ensure chastity and morality in society. It was emphasized that there is nowhere where mutilation of organs is regarded as important for tarbiyya (moral upbringing).

\section{Islam and cultural practices}

This topic was discussed in order to address one of the reasons for practising FGM/C. In the studies, it emerged that the practice was also considered a Somali cultural practice.

"It is our tradition that a girl must be circumcised and stitched..." (Married women, Wajir Baseline study).

Facilitators asserted that Islam did not come to outlaw or prohibit all cultural practices and its adherents were free to continue with their cultures and practices as long as these were not in conflict with the teachings of Islam. The participants were reminded of the following guidelines regarding Islam and cultures:

- Cultures in conformity with the teachings of Islam are confirmed as Islamic practices. For example hospitality, chastity, respect to the elderly and helping the poor etc., are upheld in many cultures and are in conformity with Islam.

- Cultures that are in conflict with Islam are either regulated to conform to the teachings or totally eradicated (e.g. polygamy was regulated, female infanticide was totally eradicated ${ }^{22}$ ).

Therefore Muslims from all tribes and communities are required to consider their cultures and take what is in conformity with Islam and avoid anything that is in conflict with Islamic teachings. In the sessions, examples of Somali cultures and traditions abandoned in preference for Islam were discussed in comparison to FGM/C. The conclusion was that where there is a conflict between Islam and culture, Islam should take precedence, and as a cultural practice, FGM/C is in conflict with Islam and should therefore be abandoned.

\section{Rights perspective of FGM/C}

Under this topic the rights of women and girls that are violated by the practice were discussed to show that it is a crime in Islam to violate the rights of others and how sinful this was in Islam.

- Right to life: The practice violates this right when some girls die during the procedure or afterwards as a result of infections or complications. A logical conclusion was then drawn showing the unlawful nature of such an act and why the person responsible for the decision to cut such a girl would be responsible for the death.

22 These are cultures that existed in pre-Islamic Arabia. 
- Right to a healthy body and integrity: Nobody has the right to mutilate parts of the body, whether their own or another person's. Participants were reminded that parents and guardians have no absolute power over the bodies of their daughters and that they were violating the girls' rights hence committing sin.

- Right to health and healthy living: Many women and girls live with lots of pain and medical complications as a result of the operation, some of which are traumatizing, thereby contributing to women's stigmatization and discrimination in the community. These are conditions brought about by this practice. Again participants were reminded that this was a violation of the rights of women and girls, and hence a sin.

- Right to enjoy sex with her husband: With the help of a medical expert, it was explained that FGM/C interferes with the sexual functioning of the women thereby denying them the right to full enjoyment of sex, and hence it is a violation of their rights and a sin.

- Right to clean worship: Infibulation makes it impossible to maintain genital hygiene thereby preventing women and girls the right to 'clean' worship (tohara).

- Right to make a choice: The girls are circumcised at tender ages of between four and ten years. They are in no position to make an informed choice regarding FGM/C and whether or not they should undergo it. This is a violation of the right of the individual, in this case the girl, to make choices in life.

\section{Medical perspective on FGM/C}

A medical expert was always called in to highlight the medical harms of the practice. The medical expert also answered questions, and clarified underlying reasons for FGM/C practice in the community and misconceptions.

- Medical harms arising from the practice, both immediate and long-term, were discussed with pictures and drawings, to illustrate the severity of suffering endured by women and girls. Emphasis was laid on the fact that all forms of FGM/C are harmful, in order to counter the belief that the so-called sunnah type has no harms.

- Participants were also informed that sexual desires are controlled by the brain and not the genitalia as is believed by the community, hence no amount of mutilation of organs can make one not indulge in sex if they so wished. In one training session, a medical doctor was categorical in stating that if there was any organ to be cut for desires to be reduced, that organ is the brain and not the clitoris.

- The expert clarified that the body organs, including the clitoris and the labia minora, grow but proportionate to the rest of the body so as to counter the belief that if not cut, these will grow long and hang loosely making women get aroused with the touch of their thighs or cloth.

- Participants were informed that the clitoris has no opening (orifice) to produce any discharge and that it was not true that it grows into folds that will harbour dirt. This was to counter the belief that, "Those who are not 
circumcised are dirty, and they will always produce a foul smell, so we are circumcised to be kept clean." (Newly married women FGD).

- The medical expert also pointed out that virginity was natural and that it meant intact hymen which could also be lost through other means and not necessarily sexual intercourse.

- The medical expert further explained the process of sexual activity and that the clitoris possesses no challenge to the male organ during intercourse.

\section{Shariah guidelines on harmful practices}

Once the participants were informed of the medical harms arising from FGM/C, Shariah guidelines on harmful practices were discussed. Islamic Shariah gives the following ruling on any harmful practice:

- Harm must be removed or stopped: adhararu yuzaalu. This is based on the Quran in which Allah (SWT) says: "...you enjoin what is right and forbid what is wrong and belief in Allah..." (3:110) and on the teaching of the Prophet (PBUH) that any harmful thing should be removed through any possible means.

- There is the golden rule in Shariah, which states: la dharar wala dhirar (Cause no harm and do not reciprocate harm). FGM/C is a harmful practice that should be avoided. Allah says in the Quran: "... and do not throw yourselves with your own hands into destruction..." (2:195).

- If something has both benefits and harms, it is only allowed if the benefits outweigh the harms. Male circumcision, for example, may be harmful but first it has been proven to be a religious practice and secondly the resulting benefits are very significant. These benefits are both religious (enhances cleanliness) and medical (may prevent cancer of the penis). As for the women, FGM/C does directly the opposite of this by interfering with their religious cleanliness and causing them harm.

- Another guiding principle is that a harm or evil is not removed or stopped by causing a greater harm. In this context the assumed harm or evil, in the view of the proponents of FGM/C, is girls' or women's indulgence in unlawful sex, which according to them can be controlled by FGM/C. The ensuing harms from FGM/C are much greater and the practice, and should thus be avoided. Besides, it has been proven that desires are controlled by the brain and hence emphasis on moral teaching.

- Harm cannot be too old and that Muslims are required to correct a wrong the moment they discover or become aware of it. This principle was quoted to correct the notion that the community has been practising FGM/C for a long time and it is hard to change. "it is hard for Somalis to stop pharaonic circumcision. It has been there and it is difficult to stop it". The Somali proverb, "qalad waa halkii laguqabtaa" was used, meaning 'a wrong is the moment it is known', hence one is obliged to follow the correct guidance and avoid doing wrong the moment he/ she knows. 
Participants were also informed that it is unlawful to cut a healthy organ from anybody for no apparent reason in Islam. Such organs can be cut for medical reasons and or meting punishment such as amputating the hand of a thief under Islamic Shariah. There is blood money that becomes compulsory on anyone who causes injury and or cuts another person's limbs. With help from the medical expert, discussion was often raised around this in order to shed light on the fact that what is cut from the women during the operations are healthy functional organs.

To many community members and especially the men, what is cut from the women is just a piece of skin comparable to the foreskin of a man and not an organ. At this juncture, the facilitators often quoted another verse in Quran that says, "for anything you do not know, ask the expert" (16:43). This verse was cited to show that the medical person is an expert in human anatomy and should therefore be listened to when he/she advices that what is cut from the women are functional organs. Many participants were taken aback when the medical expert confirmed this, went further to say that cutting of the clitoris is equivalent to cutting the penis of the man, and posed the question: how will such a man function?

\section{Reality in the communities}

This session was necessary especially for the scholars, other male community members as well as other community persons including women, because many of them argued that the common practice in the community was sunnah and that the pharaonic type (type III) was abandoned a long time ago. They often opposed our study findings which showed that the common practice within the community is type III FGM/C. However, none of them was in a position to say with certainty what actually happens and statements from the traditional circumcisers always proved them wrong. A cutter gave an account of how she does the cut, and a woman narrated her personal experience of the cut to give a detailed understanding of what the procedure entails.

\section{Evidence from the Wajir baseline study}

Key findings from the baseline study on the practice of FGM/C conducted in November 2005 in Wajir Central division were presented to all participants, as follows:

- FGM/C is virtually universal in Wajir; only one female out of the 259 interviewed was not circumcised. The prevalent type was type III (infibulation / pharaonic), the severest form of FGM/C.

- Three major reasons given for the continuation of the practice were: that FGM/C was an Islamic religious requirement; a Somali tradition; and a good tradition. Other reasons included prevention of immorality by reducing sexual desires in women, ensuring cleanliness, and that it preserves virginity.

- Over $40 \%$ of the study respondents did not know any medical harm associated with the practice. Others denied the idea of complications associated with the practice and said that any woman could become sick regardless of her FGM/C status. 
- Despite the knowledge of complications arising from the practice, there was support for the continuation of the practice and especially among the women ( $83 \%$ as opposed to $64 \%$ of the men). Those opposed were mainly young men with post-primary education.

- Respondents suggested that they were ready to listen to guidance from the religious scholars concerning the correct position of Islam on the practice. They said that they will not stop due to legislation but they are ready to stop anything that is not Islamic.

\section{Visual evidence}

Illustrations and pictures of the different types of the practice were used for explanations. Many participants were shocked and could not believe the change in the genitalia after the operation. In one of the sessions, one old scholar repeatedly asked if what he was seeing was real, and when confirmed made a fatwa (religious ruling) that no infibulated Somali female was religiously 'clean' and therefore they should just go out and start community education as those women's worship (ibada) was compromised.

A video documentary on an Ethiopian community showing a young girl being cut was often shown to the participants ${ }^{23}$. After every session, participants were asked to give comments. Some of the comments from participants are sampled below:

- Young innocent girl, happy at first and later sadness engulfed her

- Shocking to watch

- Inhuman act

- Unhygienic conditions

- Brutal

- Ambushing

- Painful (wails from the girl as her stomach was moving up and down)

- Lots of bleeding

- Too cruel

- It cannot be a religious practice

- Barbaric

- New to me, I never imagined anything like this happens

- It is not only the circumcisers who will answer lots of questions, even us as parents since we take our girls to them, they don't force us

"I have been cut but I never thought it is this bad. Seeing the young girl being cut into pieces made me sick inside and I felt like vomiting. It is very cruel and I think the

23. Documentary scarred for life by The National Committee on Traditional Practices in Ethiopia. 
circumcisers have a lot to answer before God. This thing must stop" said a women's leader in July 2007.

\section{"Women are truly doing the work of satan if this is what they call circumcision because this is butchering the poor girl. I am so disturbed and thank you very much for sharing this with us. Truly it is a torture and I agree this thing must stop!" said a male leader in July 2007.}

Female participants always agreed that the type of cutting shown on the video was exactly what was happening in Wajir and what was done to them, except for the stitching (in the video, there is stitching of the cut areas using thread and thorns).

\section{Circumciser's testimony}

A circumciser was invited to give an account of how she cuts the girls especially for sessions with the religious scholars. Many circumcisers said they were still cutting as it was done in the old days and did not know the sunnah type. Others claimed that they did both and it was the mother of the girl who would decide which type she wanted for her daughter:

"I start cutting from the top of the clitoris (holding her nose and pointing at its base in demonstration), then follow it with the labia minora (from the nose she moves to her upper lips in demonstration). I scrub the labia majoras (shows this by turning her upper lip to show the inner lining and demonstrating how she scrubs with the razor) so that I am not accused of leaving any parts. Then I close the labia majora together (holds her lips together) and apply malmal exactly the way my mother taught me. Then I tie the legs from the thighs to the toes" (Circumciser, $1^{\text {st }}$ Religious Leaders Consultative Meeting, June 2006, Wajir).

It was apparent that all of them doubled up as traditional birth attendants (TBAs) and knew how to administer injections such as anti-tetanus and antibiotics. They also said they gave the girls local anaesthesia before cutting them to ease the pain. This proves that there is medicalization of the practice as well as the unintended side of equipping and training the TBAs. Actually, one of them claimed that she was taught how to carry out the 'preferred' sunnah type in one of the trainings she received as a TBA.

\section{Personal experiences}

To aid discussion on the reality on the ground, a woman would give her personal experience of the pain, trauma and complications she suffered as a result of FGM/C. This was intended to make the men (especially scholars and leaders), who do not have first-hand experiences of what happens, to understand the severity of the practice. It was meant to make them appreciate the suffering of these women who undergo FGM/C, and who might subject their daughters to it, as a result of ignorance on what Islam says about FGM/C. This narration helped show that Somali women are not happy with what they undergo and were only suffering in silence. This was also meant to make these leaders, more so the scholars, realize that 
they are the people endowed with Islamic knowledge and therefore are under an obligation to guide the community by correcting the misconceptions.

\section{Pre- and post-training tests}

Participants, who were literate such as the youth and teachers, were given written pre- and post-training tests to do to assess their understanding of the practice before and after the training as well as their perceptions and intentions to abandon the practice. Those who were not literate were asked to state their understanding at the beginning and at the end of the workshop. Their opinions were sought by show of hands. There was always considerable mind-change in all sessions, which shows the importance of sustaining community dialogues.

\section{Responsibilities of leaders in the community}

Through a sermon from one of the facilitators, participants in all trainings and especially leaders (religious, men, women, teachers and youth) were reminded of their responsibilities within the community, especially concerning educating and being role models to the community. They were reminded that they would be held accountable for ills in the community for which they can correct but have chosen not to. Each group was reminded that they should begin with their families and reach those they can.

\section{FREQUENTLY ASKED QUESTIONS}

In all discussion groups the following questions were asked frequently:

\section{Why is FGM/C being discussed now? Is it because America is against it? What is the hidden agenda or motive of those opposed to the practice?}

In each session, this was the first question to be asked, especially after clarifying the Islamic perspective. Participants asked whether a new version of Islam has been discovered or invented. This was clarified using the hijab (Islamic dress for women) as an example. The participants would be asked when the Somalis started wearing the dress and at most this was pointed out to be the last fifteen years. They would then be asked why fifteen years yet the hijab has been revealed in the Quran over one thousand and four hundred years. It was further explained that the Somali community did not become Muslims fifteen years ago nor was there a new Islam. Participants always said that it was because the people did not know that this was a requirement and therefore continued wearing their traditional dress. In other words it was agreed that knowledge that the hijab was a must was lacking in the community even though there were learned religious scholars in the community. Participants were then informed that just like the hijab was not known before so is the practice of FGM/C and Islam. The practice was left unquestioned for a long time and that its un-Islamic nature has been understood now. Islamic guidance on the fact that a wrong be stopped once realized was applied and the Somali saying, 'qalad waa halkii la gu qabtaa' (a wrong is corrected when it is known) was also used to cement this further. 
Other examples of habits in the community, initially taken as acceptable in Islam, were cited, such as Miraa (khat) chewing which many people in the community now denounce as un-Islamic. Participants were then asked if they should doubt the motive of anybody who comes to question Miraa, who establishes rehabilitation centres for the addicts and/ or facilitates alternative business for the sellers. All agreed that such a person would be addressing a pertinent issue in the community. After all the presentations, this discussion was revisited and most participants agreed that FGM/C is indeed a pertinent issue that calls for concerted effort to address it, and that the discussions were timely if not long overdue.

Why are we hearing FGM/C is not Islamic yet we have had scholars amongst us for a long time? Why are the religious scholars not taking a lead in clarifying the Islamic verdict (hukm) on FGM/C?

Challenges facing scholars in addressing FGM/C were discussed in all their meetings. These challenges were then shared with community groups. Some of the challenges pointed out include:

- No consensus among the scholars on FGM/C. They have different opinions and different interpretations and not all scholars are ready to talk about FGM/C.

- Many scholars are embarrassed about discussing female genitalia, and have negative attitudes towards female sexuality, and so avoid doing so.

- The scholars do not prioritize FGM/C as a religious, health and human rights issue in the community. A lady scholar in Wajir told several sittings that FGM/C was not an issue they addressed before the USAID-funded FRONTIERS FGC project:
"When Maryam"2 came to Wajir to roll out the FGM/C programme it was a shocker to me. Her approach was very good and she came with other learned scholars who debated with us on the issue. Being a woman scholar I had never looked at this fundamental female issue before, together with my other colleagues we were busy dealing with issues of Hijab (Islamic dress), salah (prayers) and other issues of worship and never looked into the basis of this practice in Islam, how it affected the women and whether it was acceptable or not..."

- Any discussion on FGM/C is seen as a western-anti-Muslim activity, and so scholars are sceptical of the motives behind those supporting the activity. Scholars are scared of losing credibility and being called 'pro-western' if they openly oppose this tradition.

- Many scholars are ready to denounce the practice in private, and even protect their daughters from it but feel unable to argue against it in public for fear of being perceived as pro-western.

- FGM/C is a strongly held tradition and will require sustained education and debate to influence behaviour, but many donors can only fund shorter-term projects. 
About local scholars not taking the 'lead' in discussing FGM/C, participants were reminded that nobody has the monopoly to talk about Islam and there is no spokesperson for it. Anyone who has the correct information from the authentic sources is obliged to pass it on and correct ills in the community. Therefore scholars, whether Somali or non-Somali, have the responsibility to correct and guide the community.

\section{ACHIEVEMENTS}

- At the national symposium held in Mombasa in June 2007, all non-Somali scholars, including those from Tana River and upper Eastern districts who come from communities that practice FGM/C, stood firm that the practice has no basis at all in Islam. These scholars can be used to engage further with the Somali scholars and also educate the community to encourage abandonment.

- The regional symposium, held in Garissa in September 2006, led to an agreement that the so-called sunnah type of FGM/C is actually a mubaah practice. This is an act that is permissible for Muslims, but for which there is no religious benefit if practised and no harm if not practised. This is very different from a sunnah act, which does have religious rewards and virtues associated with its practice. This agreement was a break-through, because it is easier to use this position to publicly question the continuation of the practice as it has no authentic basis in Islam and no associated rewards, and so all the physical and psychological harms are incurred without any corresponding benefit.

- Some scholars have said that they would protect their daughters from FGM/C. This is a strong message to communicate to the community because these scholars are role models and the community may be encouraged to follow their example.

- Many scholars are also convinced that FGM/C is a non-Islamic practice but are not yet willing to publicly state their position. Some have been able to declare their stand notably eleven scholars (5 in Wajir, 2 in Garissa, 2 in Moyale and 2 in Tana River).

- For many scholars and other community members, this series of meetings were their first opportunity to witness FGM/C being discussed or questioned from a Shariah perspective.

- Many community members, especially the men, had little understanding of what FGM/C actually entailed. This changed with the help of a video documentary, drawings and pictures, as well as explanations from medical experts.

- The presence of female scholars and other female leaders added much value to the debate, from both an Islamic and women's perspective. Male scholars were impressed and surprised that Somali women could voice their opinions so clearly 
and were strongly opposed to FGM/C, because they always thought that all women were strongly in favour of the practice.

\section{LESSONS LEARNT}

- The clarification that FGM/C is not Islamic is a powerful tool and messages around its non-Islamic nature were instrumental in convincing the community members. In all the meetings we had, there was considerable mind-change among participants. This is evident from:

- The pre- and post-training tests

- Show of hands for those in support or opposed to the practice before and after the training

- Cutters always cried and asked if they can seek forgiveness. There is hope here especially if they so decide to stop cutting

- Scholars can play a critical and influential role in community education and encouragement of FGM/C abandonment. However, these scholars are members of their community and most still support all the cultural reasons for the practice. Discussions, debates and exposure meetings between them must be sustained to lead to the mind-change among these key leaders which is a prerequisite for community-wide abandonment.

- It became evident that it is much more effective to engage a small number of scholars during the discussions. When a large number are gathered, there is a tendency not to question the status quo and to defend an existing position without objectivity.

- The Arabic language is complex and requires a deep knowledge to be able to fully understand the Islamic texts, as well as to avoid taking things at face value. Many scholars suffer from insufficient understanding of the language in interpreting some of the ahadith and other Islamic texts. For example the word alkhitaan, which is in one of the prominent Hadith and is used by proponents of the sunnah circumcision, actually refers to male circumcision only, whereas the circumcision of females is called al-khifaad in Arabic.

- In all meetings with the Islamic scholars, the verdict on the practice has moved from being considered sunnah (at district discussions) to mubah (at the regional symposium) to the point where it was declared non-Islamic (at the national symposium) though by a majority non-Somali scholars. This shows the importance of sustained discussions and debates among the scholars.

- The regional and national symposia were attended by scholars from Saudi Arabia and Sudan respectively. Exposure to Islamic scholars from a different perspective is important for the local Somali scholars to enable them to meet with their peers who have a different opinion on the practice.

- Even after clarifying the non-religious basis of the practice, participants were worried about whether they will still be able control their girls so that they do not 
practice sex before or outside marriage. This suggests that their real concern is controlling female sexuality and that FGM/C is seen as the best way to do this; the religious justification is used to give greater support for this rationale.

- Many women do not consider the practice a priority problem for themselves or the community. Marriageability reason for FGM/C practice is very strong and there are no much counter arguments to help women move from the concerns about getting married.

- Many myths and anecdotes help to reinforce continuation of the practice. These need to be discussed and analyzed from an Islamic and cultural perspective to clarify the true situation. For example, in one of the sessions, a circumciser narrated the following story when asked what problems she foresaw if girls were not circumcised:

"There was an uncircumcised girl who went to a place far away from Wajir, beyond Marsabit ${ }^{25}$, to look after cattle with her brother ${ }^{26}$. After drinking the milk and living on fats and meat, the girl became mature and began to have desires for men. She would cry out loud in the evenings just like a he-goat 27 . She knew she could not get married as she had to help her brother and also because they were away from their home. She asked the man who she wanted to kill her brother. She told this man and his friends to kill her brother when he would be milking a certain cow. She gave them the name of the cow and said she would call out to the cow loudly, and when they hear the milking they should attack the brother. Luckily the man who had the knife missed the brother's neck and cut off his hair. The brother ran off to safety. The brother ran back to Wajir and told the family what had happened. Her father sent out people to bring her and the cattle back. He then ordered her to be killed and her abdomen opened up. An animal/organism ${ }^{28}$ was removed. It could not be killed and only after semen was brought and poured into its mouth did it die. This is what would eat the girls if left uncircumcised and the reason why they will run wild after men" (Wajir, July 2006).

Marsabit town is in Marsabit district of Eastern Province in Kenya It is a common practice for young men to take the family's animals to distant places where there is good pasture and leave behind the rest of the family. This is called jilley in Somali. She used the local terms qoobaad and edaad (to depict the extent of the pain making her cry out). definitive). 


\section{WAY FORWARD}

\section{Continue with religious clarifications}

Because the scholars are divided on the correct stand of Islam on FGM/C, consensus building among them through group discussion and debate needs to continue to support community education activities. Emphasis should be placed on exposing them to other Muslim scholars and communities opposed to the practice, including scholars from Somalia, Sudan, Saudi Arabia and Egypt.

There are many non-Somali Muslim scholars who are opposed to the practice who can be used for community education because no one scholar has the monopoly of Islamic knowledge and a non-Somali scholar can educate the Somali community, provided the matter is tackled from a religious perspective.

\section{Mainstreaming FGM/C in other development programs}

North Eastern Province is a region that is lagging behind in development and due to the many natural calamities afflicting it, there are lots of challenges. It sometimes becomes difficult to engage in discussions on FGM/C with people who are moving around in search of basic necessities like water and food. The program should expand to include some practical as well as strategic needs of the community, especially those of women and youth. Working with the religious scholars as change agents is vital in this community; they can be used for other programs that are related to FGM/C. For instance, clarifications around the gender and human rights implications of FGM/C from an Islamic perspective will be useful for expanding the horizon to include reproductive health (RH), family planning (FP) and HIV/ AIDs in the community education campaigns.

\section{Strengthen partnerships}

Given the challenges mentioned above, it is important to seek partnerships with other development partners working in the region so as to share expertise and resources to enhance the campaigns. Partnership with Islamic Faith-Based Organizations is very crucial.

\section{Target the whole community}

Adult women (as mothers and as practitioners), as well as men (especially the youth), uncles, aunties and grandmothers, are all part of the immediate and the extended family who have a say in decisions concerning FGM/C on girls. It is critical, therefore, to reach out to all groups within the community during discussions. In addition, others in leadership positions in the community should be engaged during community education, e.g. political and civic leaders, community elites/professionals, teachers, community-based organizations (CBOs)/nongovernmental organizations (NGOs), medical personnel, and government administration. 


\section{Target the youth}

The youth are the future parents and need special emphasis in order to save future daughters from FGM/C. Many are educated and it is much easier to convince them with facts. Since girls are cut at a tender age in the community, it is vital to have the parents saying no to the practice, hence the importance of targeting the youth early enough.

\section{Use of mass media}

Many people in the community listen to the radio and five stations in particular will be important: the local radio stations, Star FM and FRONTIER FM, which are available in Nairobi, Garissa and Wajir; the Kenya Broadcasting Corporation Somali service; the BBC Somali service; and IQRA FM in Nairobi and its environs. Opportunities to raise this debate through these stations as well as through television (TV) should be explored, in addition to other mass media channels such as posters, public address systems for the religious scholars, films/documentaries, and T-shirts and Lesos / Kitenge with anti-FGM/C information.

\section{Suggestions for further research}

- Women's status and their relations with men in this Somali community need to be better understood. In such a strongly patriarchal society, women are in inferior positions and so it is difficult to argue against a harmful practice that they perceive to uplift their status. The relationship between women's decisions to stop/continue FGM/C, and desire for sexual morality, acceptable sexual behaviour and femininity needs to be studied.

- FGM/C and its association with women's sexuality is not well understood, especially whether or not FGM/C reduces sexual desires and alters their response.

- Men's knowledge and perceptions of FGM/C and their role in the abandonment of the practice is important in order to inform interventions. The Somali community is a patriarchal society and men are the decision makers. Understanding men's perceptions of FGM/C, and their personal experiences of living with wives and daughters who may suffer complications, would help highlight their role in aiding the campaign towards FGM/C abandonment.

- Understanding trends in FGM/C practice within different age groups is important to gain insights and know any change to adapt these for the abandonment process. 


\section{CONCLUSIONS}

The Population Council's FRONTIERS programme has developed a religious oriented approach to address the practice of FGM/C among the Somali ethnic community living in Wajir district of North Eastern Province in Kenya. This approach was developed to respond to the community's stand on FGM/C, which is most commonly presented as being an Islamic requirement within the Somali culture.

Community members had indicated that they were ready to listen to religious scholars and would be prepared to stop any practices that are not in line with Islamic teachings. To be able to do so, it was important that religious scholars within this community clarify among themselves the correct position of Islam on FGM/C. This was undertaken through facilitating a critical evaluation of the evidence cited by proponents of FGM/C, to demonstrate that there is actually no Islamic basis to the practice. Discussions around this have concluded that proponents mostly rely on ahadith that are either weak or unrelated to FGM/C. Weak ahadith cannot be relied on to guide Muslims in their behaviour, especially if they contain anything that is harmful to the well-being of people, as is the case with FGM/C. Deeper analyses of Islamic teachings can help counter the practice by showing that it is actually in violation of Islamic Shariah.

Discussion topics dwelt on bringing forth a format using logical arguments to counter the underlying reasons for carrying out FGM/C. Similar discussions were held for other community groups in Wajir. This approach has led to some religious scholars and community members openly declaring their opposition to the practice, and many more privately opposing the practice though unwilling to debate the issue in public.

The next steps in this endeavour should include sustaining engagement with religious scholars to support them in convincing their communities to abandon the practice, encouraging those scholars who are privately against the practice to speak out, and undertaking discussion sessions with a range of other community groups to communicate these messages to all involved in decisions concerning the practice. 
Frontiers in Reproductive Health

Population Council

4301 Connecticut Avenue, N.W.

Suite 280

Washington, D.C. 20008

USA

Telephone: 202-237-9400

Facsimile: $\quad$ 202-237-8410

E-mail: $\quad$ frontiers@pcdc.org

Website: $\quad$ www.popcouncil.org

AfRICA

Population Council Regional Office

P.O. Box 17643

Nairobi

Kenya

Telephone: $\quad$ 254-2-2713480/1/2/3

Facsimile: $\quad$ 254-2-2713479

E-mail: $\quad$ publications@popcouncil.org

AsIa AND THE NeAR EAST

Population Council Regional Office

Ground Floor, Zone 5A

India Habitat Center

Lodi Road

New Delhi 110003

India

Telephone: $\quad$ 91-11-461-0913

Facsimile: $\quad$ 91-11-464\2903

E-mail: $\quad$ frontiers@pcindia.org

Latin America AND tHe CARIBbeAn

Population Council Regional Office

Escondida 110

Villa Coyoacan

04000 Mexico, D.F.

Mexico

Telephone: 52-5-659-8537

Facsimile: 52-5-554-1226

E-mail: $\quad$ disemina@popcouncil.org.mx

The Population Council is an international, nonprofit, nongovernmental institution that seeks to improve the well-being and reproductive health of current and future generations around the world and to help achieve a humane, equitable, and sustainable balance between people and resources. The Council conducts biomedical, social science, and public health research and helps build research capacities in developing countries. Established in 1952, the Council is governed by an international board of trustees. Its New York headquarters supports global network of regional and country offices.

\section{FRONTIERS}

FRONTIERS is funded by the Office of Population of the UNITED STATES AGENCY FOR INTERNATIONAL DEVELOPMENT (USAID) under the terms of Cooperative Agreement Number HRN-A-00-98-00012-00 